\title{
Investigation of Bicyclic Thioketones as Triggers for Liquid Crystal Optical Switches
}

\author{
Rochelle Fisher Bradford and Gary B. Schuster*
}

School of Chemistry and Biochemistry

Georgia Institute of Technology

Atlanta, GA 30332

Supporting Information 
Table of Contents:

\section{Page}

Figure S1. ${ }^{1} \mathrm{H}$ NMR of $\mathbf{1 0}$

Figure S2. ${ }^{1} \mathrm{H}$ NMR of 11

Figure S3. ${ }^{1} \mathrm{H}$ NMR of 12

Figure S4. ${ }^{1} \mathrm{H}$ NMR of $\mathbf{1 4} 6$

Figure S5. ${ }^{1} \mathrm{H}$ NMR of $\mathbf{1 5}$ ‘ 7 


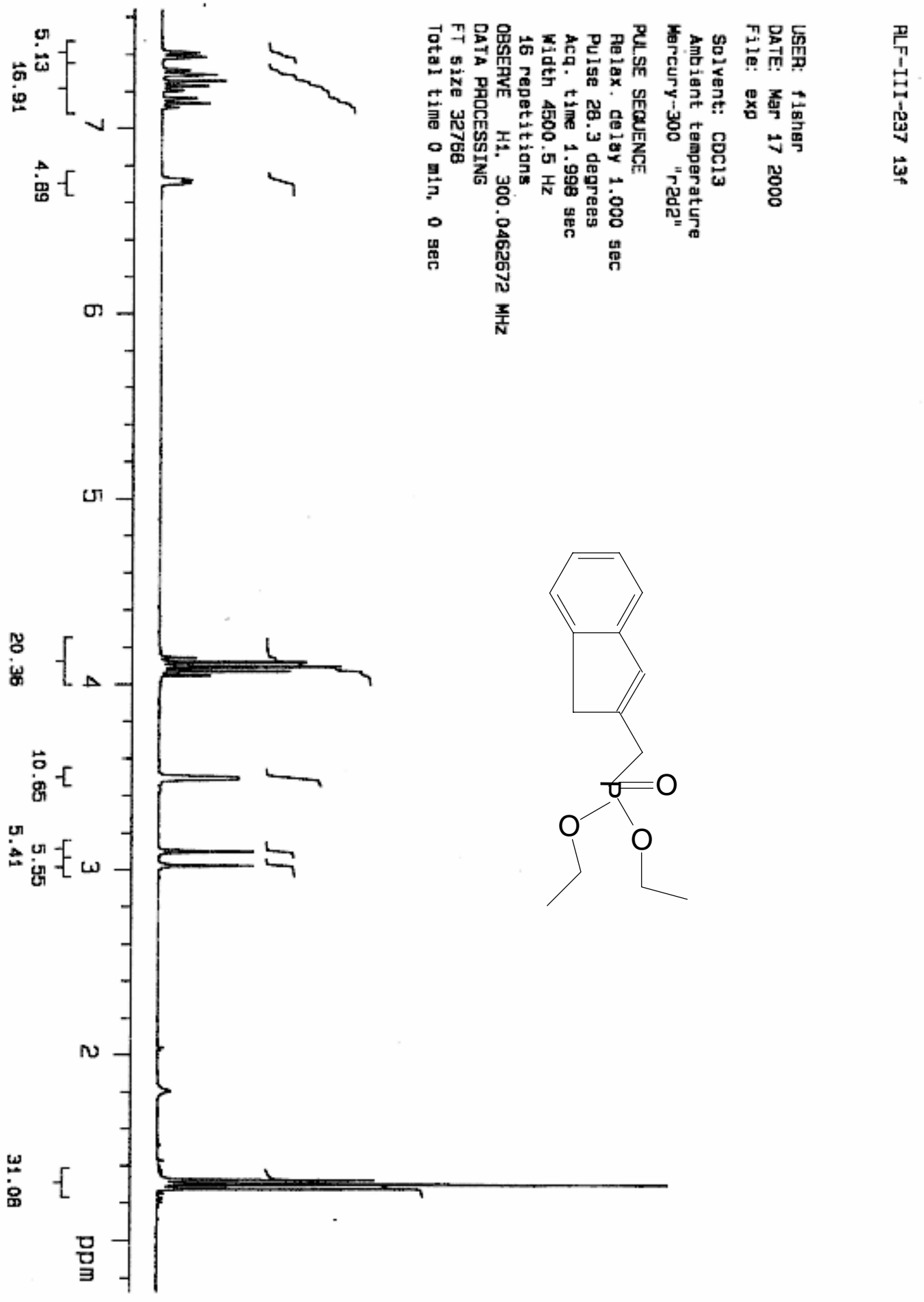

Figure S1 ${ }^{1}$ HNMR 10 


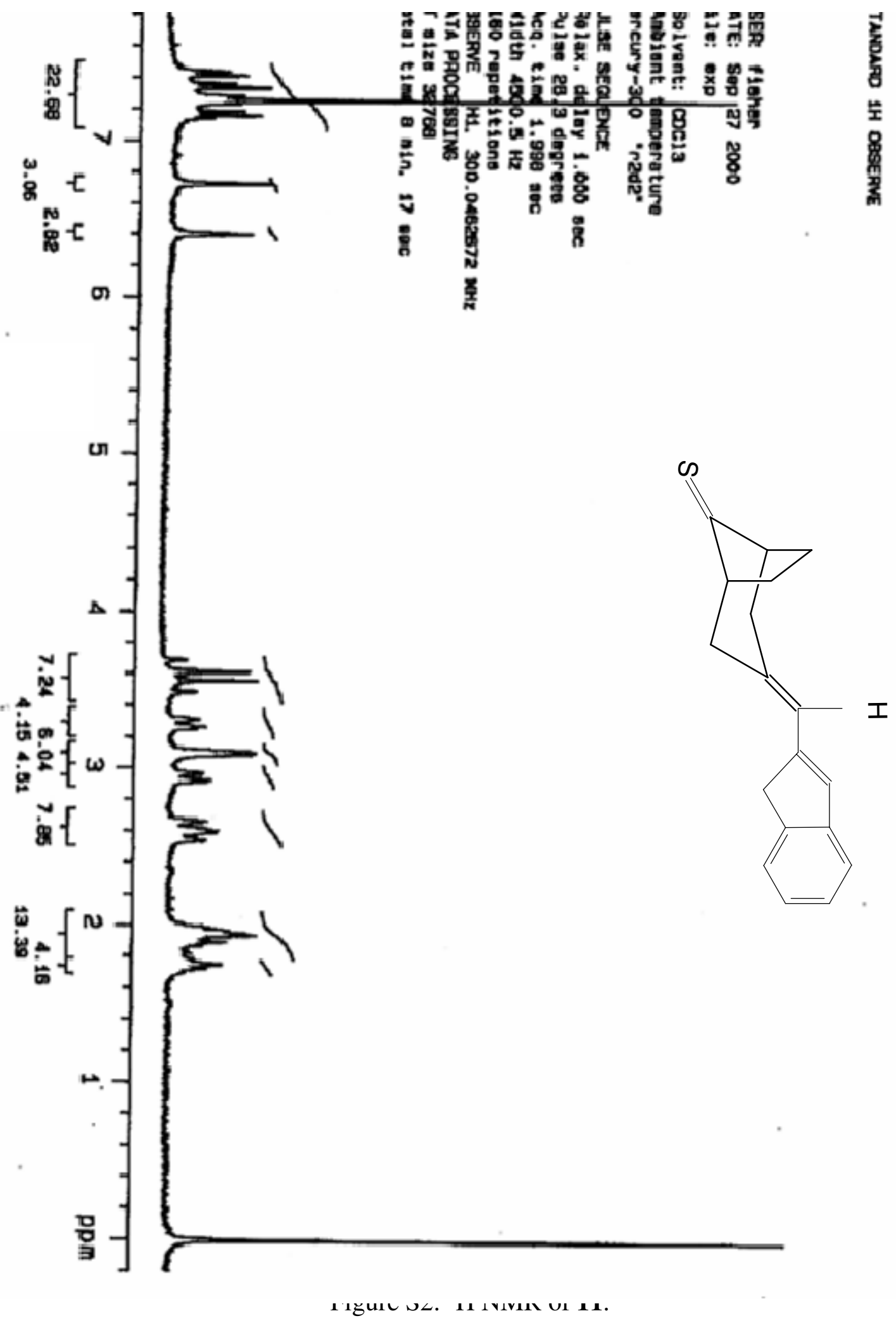




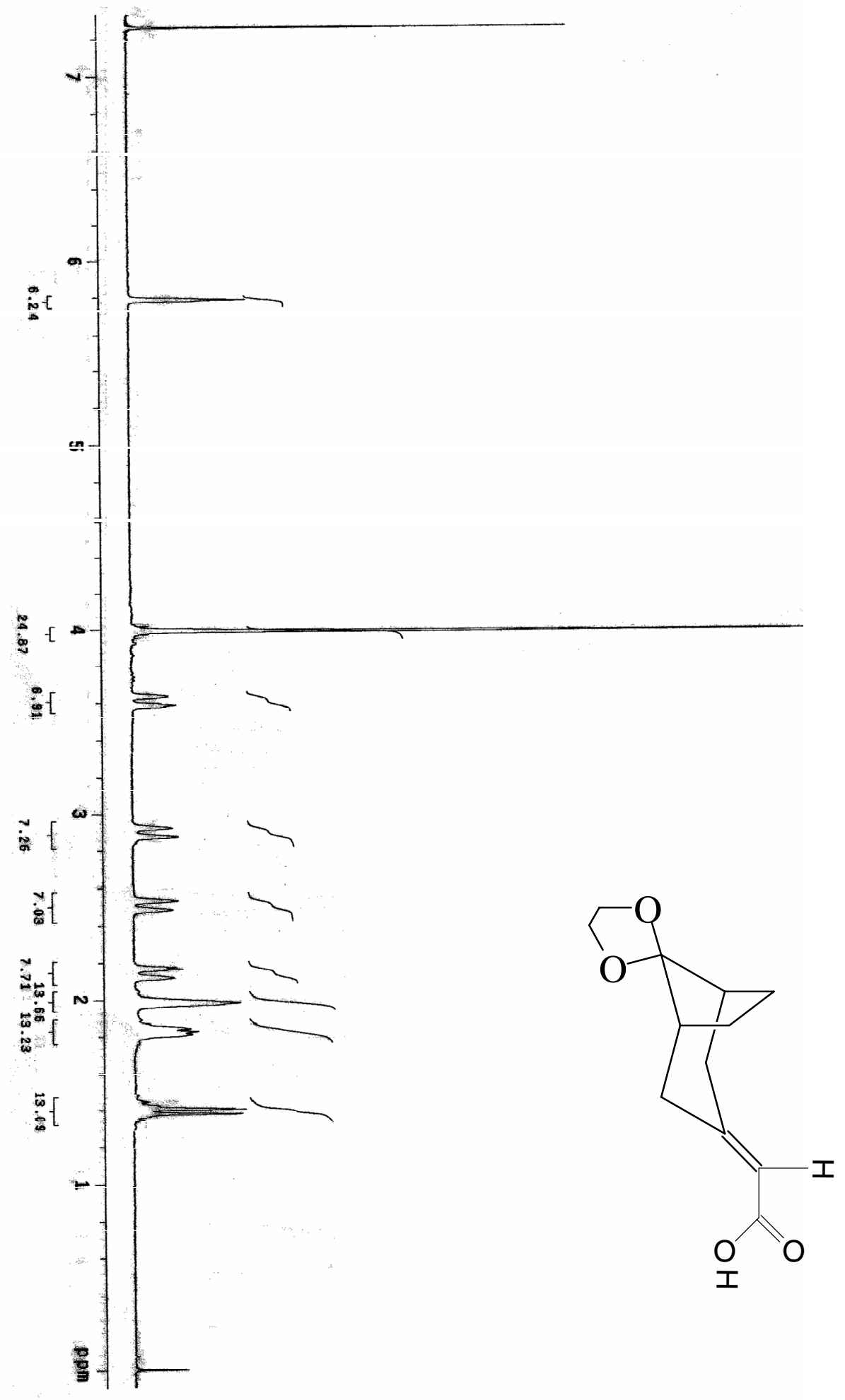

Figure S3. ${ }^{1} \mathrm{H}$ NMR of 12. 


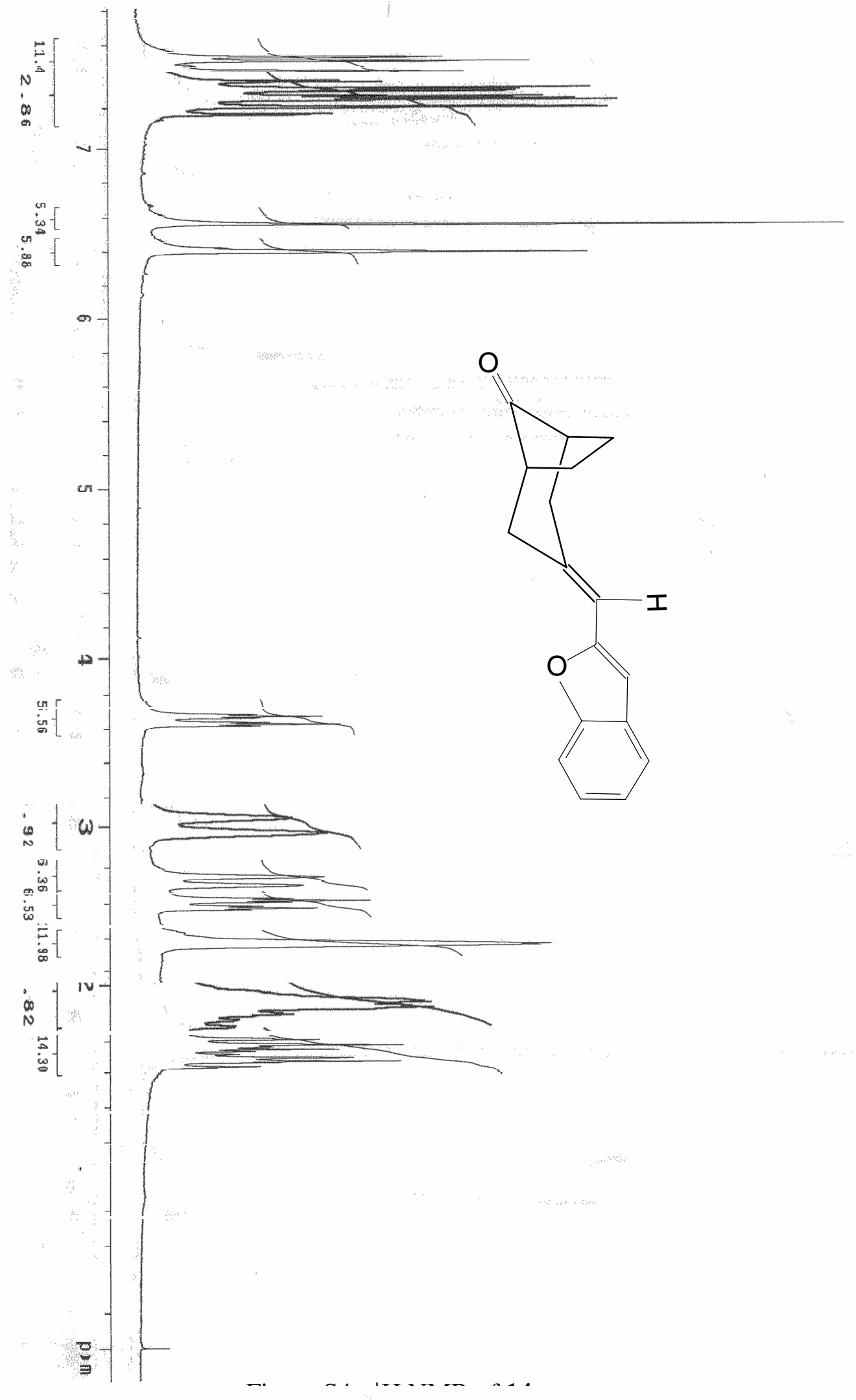




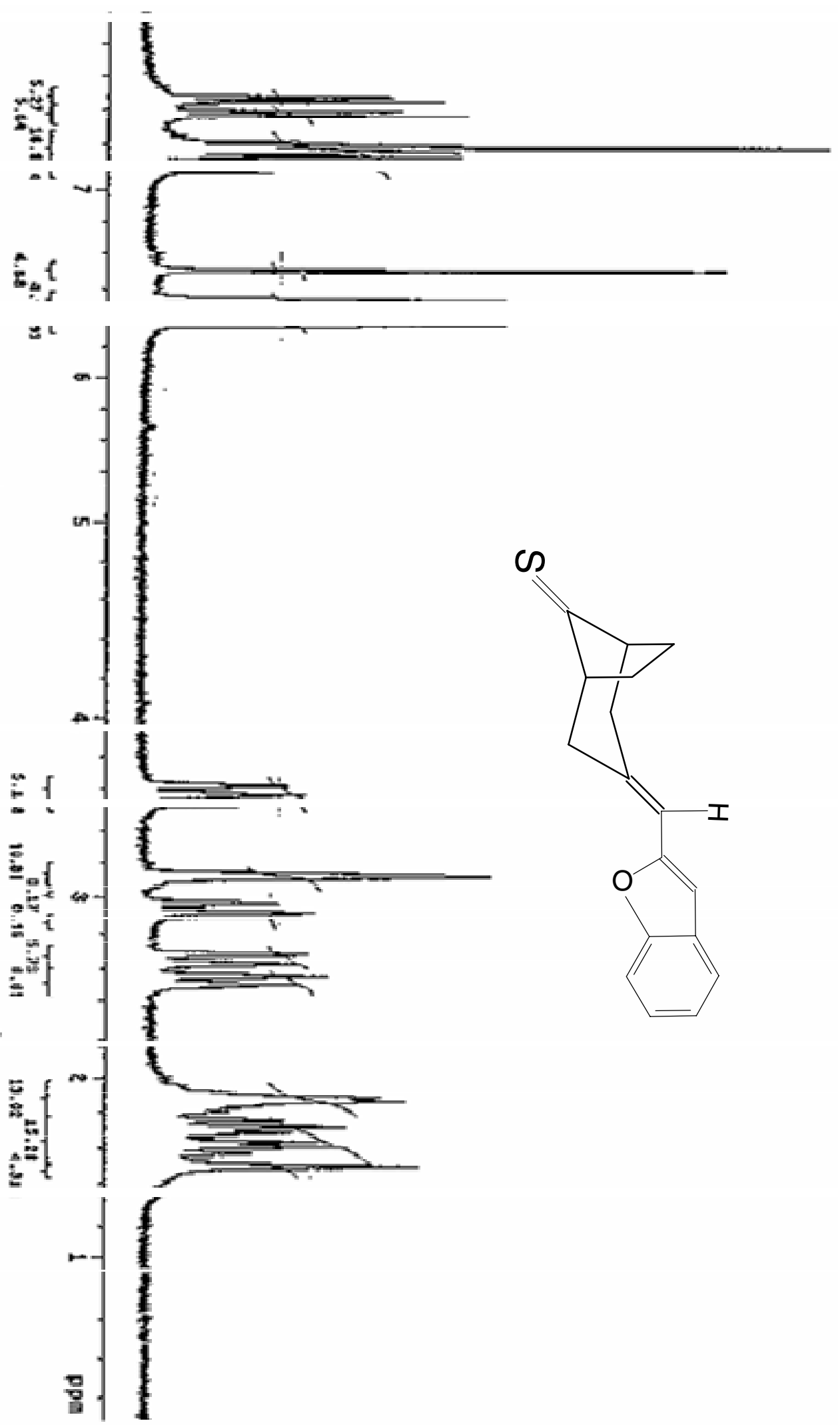

Figure S5. ${ }^{1} \mathrm{H}$ NMR of 15. 